\title{
Japanese elders lose their grip on university appointments
}

\section{Tokyo}

JAPAN's Science and Technology Agency has introduced a radically new research system that breaks with the tradition of tenure for academics.

The International Frontier Research System was set up last year at the Science and Technology Agency's Institute of Physical and Chemical Research (RIKEN) near Tokyo with funding of Y1,100 million ( $\$ 7$ million) in the first year rising to Y1,500 million in fiscal year 1987. The programme, scheduled to run for 15 years, consists of 40 researchers in seven teams, split into two groups, "Frontier Materials" and the "Biological Background of Homeostasis". A group to study the artificial brain may be added later.

The rigid system of tenured appointments has long been regarded as a weakness of Japan's universities and research institutes. Professors, once established in a chair, remain entrenched until retirement and enjoy almost dictatorial power over younger researchers who wait patiently in line for a post to be vacated.

Attempts have been made to introduce greater fluidity and flexibility into the system. When the Okazaki institutes for joint university use were set up there was heated debate over whether professorial appointments should be non-tenured. But in the end the only change was a system of adjunct professorships.

The Frontiers system parts from tradition in two respects. About one-third of the researchers, including three of the team leaders, will be non-Japanese. Second, all researchers will be employed under one-year contracts renewable up to a maximum of five years.

The system aims at funding basic research by young scientists that will "sow the seeds of technology in the 21st century", according to Takashi Bito, deputy director of the programme. Patent rights for technology arising out of the research will be shared equally between the Japanese government and the inventor. Frontiers thus in some respects resembles the agency's ERATO programme (see Nature 305, 373; 1983); although Bito says ERATO is more technology-oriented.

The homeostasis group has four teams. Gabriel Gachelin of the Pasteur Institute of France will head the chromosome team, which will study homeostasis and ageing at the gene level. Koichi Chitani, formerly of the University of Washington, heads the ageing process team, which will concentrate its research efforts in the first year on proteins associated with Alzheimer's disease, such as paired helical filaments. Masaki Furuya will resign from Tokyo University to lead research by the plant homeostasis team into phytochromes, and Tomotari Mitsuoka's intestinal flora team at RIKEN will continue to investigate the role of intestinal bacteria in health, nutrition and ageing.

With the rapid 'greying' of Japanese society (see Nature 321, 553; 1986), politicians, academics and pharmaceutical and biotechnology companies are turning their attention to the problems of old age. Researchers from Snow Brand Milk Products, Meiji Milk Products and Nissin Flour Milling Co. will join the intestinal flora team, and special facilities will be set up at RIKEN for raising aged mice and rats.

The three teams of the Frontier Materials group will carry out basic research into the development of new electronic and optical devices. RIKEN's Susuma Namba will head the quantized elements and devices team which will use electron, laser, molecular and ion beams and atomic-layer epitaxy to develop ever smaller electronic devices (such as integrated circuits and Josephson Junctions). Already down to the 100 Angstrom level, Namba works in the realm where quantum effects and electron-wave interference can be observed, and he foresees a new line of engineering emerging from his research, based on electron waves as opposed to electromagnetic radiation.

The non-linear optics and advanced material research team will be headed by Anthony Garito of Pennsylvania University, and will aim at developing non-linear optical devices and two-dimensional superconductors using organic materials, such as methyl nitro aneline. Kevin Ulmer of the Center for Advanced Research for Biotechnology at Maryland State University will lead research by the bioelectronic materials team into electro-and photoactive proteins from which should emerge new biosensors and, perhaps, the biochip. Canon Inc., Ajinomoto Co., Unitika Ltd and other Japanese and US companies are interested in joining the two teams.

But although there seems to be no lack of researchers for Frontier Materials, some of the Homeostasis teams concerned with basic biology are finding it hard to recruit members. Young and talented Japanese researchers, although initially interested, balked at the prospects of having to find a new job after five years. Problems of job security do not arise for the Japanese team leaders themselves - all are at or approaching retirement age, and several hold parallel appointments outside the Frontiers system. A true revolution will have occurred only if younger leaders are appointed when the system undergoes a turnover in staff five years hence.

\section{4,000 Chernobyl deaths?}

A NEW report from US government estimates that there will be 4,000 excess cancer deaths in Europe and 10,000 in the Soviet Union as a result of the Chernobyl disaster. The report was prepared by the Nuclear Regulatory Commission in the United States. The excess cancers will probably be indistinguishable from the $\mathbf{7 0}$ million cancer deaths that are predicted in the European area affected by the fallout over the next 70 years. Chernobyl-induced cancers might be more noticeable in the Soviet Union, where 9.5 million deaths from cancer are otherwise predicted. Estimates of the number of deaths have varied widely; these figures lie at the conservative end of the spectrum.

Soviet drilling project snag

A US delegation poised to travel to Moscow last weekend to sign a memorandum of understanding making the Soviet Union an official member of the Ocean Drilling Program was ordered not to leave just one day before the scheduled trip. The Defense Department postponed the signing by raising concern about technology transfer through Soviet participation in the project. The Soviet Union would have been the eighth participant in the project, and would have contributed more than $\$ 1$ million in membership dues for the current fiscal year. $\square$

\section{Cold closes nuclear post}

ONE of the three 'nuclear-monitoring' stations installed by a US team in Kazakhstan last year has been put out of action as a result of the severe cold last month. On the night of 16-17 January, the low temperatures at the Bayan-Aul station produced a short circuit which started a fire. Although the monitoring instruments installed in the boreholes remain unharmed, the fire destroyed a building containing all the recording equipment, without which the monitoring programme cannot function. The staff quarters at the site were also destroyed, without loss of life.

\section{Solar power for Cuba}

DR Rosa Elena Simeon, president of the Cuban Academy of sciences, has formally inaugurated Cuba's prototype solar power plant at the Santiago de Cuba solar energy research station.

Cuba has no fossil fuels and its rivers are insufficient for normal hydroelectric generation. Accordingly, as President Fidel Castro stated last July, the construction of thermal power stations will stop, to be replaced by nuclear power, boosted by pumped storage hydroelectricity at peak periods, and some solar power. (Cuba's first nuclear power plant at Gienfugos will have four 4,000 MW Soviet VVER reactors, and will be 'complemented' by a pumped storage plant at Fomento.) 